\title{
Lead extractions: dissecting adhesions up to the lead-tip of the right ventricle: safety and success-rates
}

\author{
Olivier Witte ${ }^{1}$, Peter Delnoy ${ }^{2}$, Abdul Ghani ${ }^{1}$, Jaap Jan Smit ${ }^{1}$, Anand Ramdat Misier ${ }^{1}$, \\ Arif Elvan ${ }^{1}$, and Ahmet Adiyaman ${ }^{1}$ \\ ${ }^{1}$ Isala Klinieken \\ ${ }^{2}$ Isala klinieken
}

February 12, 2021

\begin{abstract}
Objectives and Background: Goal of Transvenous Lead Extraction (TLE) is complete removal of all targeted leads, without complications. Despite counter traction manoeuvres, efficacy rates are often hampered by broken right ventricle lead (RV-lead) tips. Mechanically powered lead extraction (Evolution sheath) is effective, however safety of dissection up to the lead tip is unclear. Therefore, we examined the feasibility and safety of RV-lead extraction requiring dissection up to the myocardium. Methods and results: From 2009 to 2018, all TLE in the Isala Heart Centre (Zwolle, The Netherlands) requiring the handpowered mechanical Evolution system to extract RV-leads $(n=185)$ were examined from a prospective registry. We assessed 2 groups: TLE with the first generation Evolution $(\mathrm{n}=43)$ with $(\mathrm{A} 1, \mathrm{n}=18)$ and without $(\mathrm{A} 2, \mathrm{n}=25)$ adhesions up to the myocardium and TLE with the Novel R/L type $(n=142)$ of sheath with $(B 1, n=59)$ and without $(B 2, n=83)$ adhesions up to the myocardium. Complete success rate in Group B was significantly higher than group A (96.5 vs 76.7\%, p=0.0354). When comparing the patients with adhesions up to the myocardium, total complete success is higher in the R/L group (61.1\% vs $90.5 \%, \mathrm{p}=0.0067)$. There were no deaths. Overall major complication rates were low $(2 / 185 ; 1.1 \%)$ and there was no statistically significant difference in major and minor complications between the two groups. Conclusion: Extraction strategy with the bidirectional Evolution R/L sheath for right ventricular leads with adhesions up to the myocardium is safe and feasible.
\end{abstract}

Lead extractions: dissecting adhesions up to the lead-tip of the right ventricle: safety and success-rates

Olivier A. Witte MD, Peter Paul HM Delnoy MD PhD, Abdul Ghani, MD PhD, Jaap Jan J. Smit, MD $\mathrm{PhD}$, Anand R. Ramdat Misier, MD PhD, Arif Elvan, MD PhD, Ahmet Adiyaman, MD PhD

Department of Cardiology, Isala Heart Centre, Zwolle, the Netherlands

Word count: 3961

Correspondence: Dr. P.P.H.M. Delnoy, MD PhD

Isala Heart Centre

Department of Cardiology

Dr. Van Heesweg 2

8025 AB Zwolle

The Netherlands

Tel - 31384242000 
Fax - 31384243222

E-mail: owitte@gmail.com

Conflict of interest: none declared

Funding: there are no relationships with industry

AbstractObjectives and Background: Goal of Transvenous Lead Extraction (TLE) is complete removal of all targeted leads, without complications. Despite counter traction manoeuvres, efficacy rates are often hampered by broken right ventricle lead (RV-lead) tips. Mechanically powered lead extraction (Evolution sheath) is effective, however safety of dissection up to the lead tip is unclear. Therefore, we examined the feasibility and safety of RV-lead extraction requiring dissection up to the myocardium.Methods and results: From 2009 to 2018, all TLE in the Isala Heart Centre (Zwolle, The Netherlands) requiring the hand-powered mechanical Evolution system to extract RV-leads $(n=185)$ were examined from a prospective registry. We assessed 2 groups: TLE with the first generation Evolution $(n=43)$ with $(A 1, n=18)$ and without $(\mathrm{A} 2, \mathrm{n}=25)$ adhesions up to the myocardium and TLE with the Novel R/L type $(\mathrm{n}=142)$ of sheath with $(\mathrm{B} 1, \mathrm{n}=59)$ and without $(\mathrm{B} 2, \mathrm{n}=83)$ adhesions up to the myocardium. Complete success rate in Group B was significantly higher than group A (96.5 vs $76.7 \%, \mathrm{p}=0.0354)$. When comparing the patients with adhesions up to the myocardium, total complete success is higher in the $\mathrm{R} / \mathrm{L}$ group $(61.1 \%$ vs $90.5 \%, \mathrm{p}=0.0067)$. There were no deaths. Overall major complication rates were low $(2 / 185 ; 1.1 \%)$ and there was no statistically significant difference in major and minor complications between the two groups.Conclusion: Extraction strategy with the bidirectional Evolution R/L sheath for right ventricular leads with adhesions up to the myocardium is safe and feasible.Keywords: lead extraction, ICD, pacemaker, complications, apex of right

ventricle

\section{Introduction}

Implant rates of cardiovascular implantable electronic devices (CIED) and leads have increased progressively due to expanding indications (1-3). Moreover, a higher relative incidence of CIED infections, malfunction of leads and the need for upgrading devices is observed, resulting in an increased need for transvenous lead extraction (TLE) (4-10). Although manual traction is an effective technique to remove recently implanted leads, chronically implanted leads develop fibrous adhesions around the surrounding structures and require more complex extraction tools (11-14). The techniques and tools used in the extraction of leads include traction, counter traction, locking stylets, telescoping sheaths, and powered mechanical and laser sheaths. Over the 25 years of use of sheaths and locking stylets, the majority of papers has shown major adverse events of $2 \%$ and mortality of $1 \%(4,7,8,11-15)$. With the introduction of laser, Evolution, and other techniques, success rates have increased and procedure time has decreased, even though complications have remained fairly stable. Efficacy rates are often hampered by broken RV lead tips or larger parts, because of the absence of a dedicated tool for cutting adhesions within the apex of the right ventricle. Possibly, the fact that the locking stylet sometimes can only be advanced up to the anode and not to the final end of the RV lead contributes to this. Moreover, in some cases, the locking stylet even can't be advanced up to the anode, causing breakage of the lead more proximal. Advancing a laser sheath (SLS-II laser sheath) beyond $1 \mathrm{~cm}$ from the tip of the RV-lead is off label use and cutting through fibrous tissue up to the tip of the RV with the Evolution is discouraged, because of the possibility of perforation of the right ventricle $(16,17)$. The Evolution RL cuts bidirectional and prevents piling up of lead- and adhesive material, possibly enabling usage of the sheath up to the myocardium and facilitating removal of the RV-tip in case of adhesions. Also the RL-sheath has a crown cutting edge tip, which gives the sheath more tip-control and possibly less chance of perforation of the right ventricle (see figure 1). We therefore assessed the safety and efficacy of extraction up to the endocardium, when clinically needed.Figure 1: Picture of the Evolution R/L and old EvolutionFigure 1: Left shows the RL-sheath has a crown cutting edge, which gives the sheath more tip-control and less chance of perforation of the right ventricle in compare to the right picture with the old Evolution sheath with rotational tip.MethodsFrom 2009 to 2018, all lead extractions in the Isala Heart Centre (Zwolle, The Netherlands) requiring the use of a hand-powered mechanical Evolution system 
were examined from a prospective registry. From 2013 onwards, the Evolution sheath was replaced by the Evolution RL sheath. This sheath is very similar; however, the RL sheath has a crown cutting edge and a bidirectional cutting tip, whereas the previous Evolution sheath had only a unidirectional cutting tip. To be able to investigate the incremental ability of the new sheath to extract leads that have adhesions up to the tip, we divided the study population in 4 groups: Group A1: patients with an RV lead extraction (pace/sense or high voltage) with the first generation Evolution, with adhesions up to the tip. Group A2: patients with an RV lead extraction (pace/sense or high voltage) with the first generation Evolution, withoutadhesions up to the tip. Group B1: patients with an RV lead extraction (pace/sense or high voltage) with the novel Evolution R/L, withadhesions up to the tip. Group B2: patients with an RV lead extraction (pace/sense or high voltage) with the novel Evolution R/L, without adhesions up to the tip. All procedures were performed in the operating room or cardiac catheterization laboratory by an experienced team specialized in lead extractions. Indications and complications of TLE were defined according the current guidelines $(4,7,8)$. Indications for lead extraction were classified as infection, lead malfunction, and miscellaneous. Transvenous lead extraction due to infection included endocarditis, with or without signs of vegetation on the leads, and generator pocket infections. Persistent fever or recurrent bacteremia without an apparent focus, despite profound examination, was also an indication for extraction of the entire system since a cardiac device infection could not be excluded. Lead malfunctions were established on the basis of clinically significant alterations in pacing, sensing, and/or lead impedance parameters. Lead extraction was performed using a standard stepwise approach in all patients (18). All patients underwent TLE in electrophysiology laboratories or hybrid operating room, with continuous electrocardiographic and arterial blood pressure monitoring. The procedure was performed under sedation or general anesthesia and using Transesophageal echocardiographic guidance depending on patient status and physician preference. In patients dependent on bradycardia support, a temporary pacemaker (PM) was inserted from the femoral vein. Standby cardiac surgery for the treatment of emergency complications was always available. A stiff guidewire from the right femoral vein to the right internal jugular vein for potential use of the bridge occlusion balloon (Spectranetics, Colorado Springs, CO, USA) in case of vascular lacerations was deployed at the discretion of the physician and if available in the center. After leads were dissected free from the scar tissue in the pocket, the anchor sleeves were removed and the active fixation mechanism was retracted. After that, controlled manual traction was attempted. If the lead was not easily removed, then an appropriately sized locking stylet (Liberator Universal Locking Stylet, Cook Vascular, USA) was placed, and a silk suture was tied around the lead to bind the insulation to the conductors and to keep the insulation from bunching in front of the sheath. Manual traction was again attempted with the locking stylet in place, making sure not to disrupt the lead integrity. If still unsuccessful, a hand-powered mechanical rotational dilator Evolution or the Evolution R/L sheath was used. All patients underwent the procedure under general anaesthesia supervised by a cardiac anaesthesiologist and with continuous transoesophageal echocardiographic monitoring. The Evolution handpowered mechanical dilator sheath was replaced from 2013 onwards by the Evolution RL sheath. In our experience, the Evolution RL reduces difficulty in cutting through fibrotic tissue and advancing the sheath (14). In general, because of the risk of entrapment of adhesive tissue in the Evolution sheath, we oversize the Evolution by at least 2 French. In case of a dual coil shock, we oversize by at least 3 French. The operator pulls the handle of the dilator sheath, which causes rotation of the cutting tip. The rotational mechanism of the sheath permits movement along the lead body by cutting fibrous adhesions via the distal metal tip, whereas the outer telescoping polymer sheath protects the venous wall from the metal cutting tip while advancing over the lead in the tracts free from adherences. When fibrous attachments met, the cutting tip is uncovered from the outer sheath. Once the fibrous attachments are cut, the outer sheath is advanced until another area of attachment is encountered. Whenever an adhesion at the tip of the right ventricle lead exists, we first position the outer sheath so that the blunt end is directed toward the myocardium and we retract the cutting part of the sheath. Then traction and countertraction was applied with the outer sheath as by firmly holding the outer sheath one centimeter from the heart wall and steadily pulling the Locking Stylet back; the pacing tip will be pulled into the sheath. Rotation of the sheath may help dislodge the tip. Traction on the lead and counter traction was applied during approximately 2-4 minutes. If not successful, in case of the Evolution, we accepted the lead residue in situ. In case of the Evolution R/L 
we advance the sheath by cutting fibrous adhesions up to the tip of the lead until the edge of the right ventricle myocardium. After the release of leads from fibrous tissue, the leads are pulled back into the sheath and removed. For a visual overview of this procedure see figure 1. In case of bystander leads we protect those with a stylet. Complete success of the procedure was defined as the removal of all targeted leads and all lead material from the vascular space without the occurrence of any permanently disabling complication or procedure related death. Clinical success was defined as the removal of all targeted leads and lead material from the vascular space or retention of a small portion of the lead ([?]4 $\mathrm{cm})$ in the absence of permanently disabling complications. Failure of the procedure was defined as the inability to achieve either complete procedural or (assumed) clinical success, or the occurrence of any permanently disabling complication, or procedure-related death. Major complications were defined as outcomes that were life threatening, resulted in significant or permanent disability or death, or required surgical intervention. Minor complications were defined as events related to the procedure that required medical intervention or minor procedural intervention. Cardiac implantable electronic device related infections are categorized according the HRS expert consensus (4). The study was conducted according to the principles of the Declaration of Helsinki. The study protocol was checked at the local institutional review board, but since the study describes a standard care intervention an official approval was not mandatoryFigure 2: sequential images of an extraction with strong adhesions of the RV-lead tipStatistical analysisAll variables are presented as mean $\pm \mathrm{SD}$ or as numbers with percentages, where appropriate. Normality of distribution was assessed and means or medians were reported accordingly. We grouped patients by the type of Evolution sheath that was used (Evolution group vs. Evolution R/L group). P-values between success rates in different groups were calculated by the Chi-squared test or Fisher's exact test, where appropriate. Statistical analysis was performed using latest version of SPSS statistical software.ResultsIn total, 209 patients underwent an extraction with the Evolution $(\mathrm{n}=57)$ or Evolution R/L $(\mathrm{n}=152)$ of which 185 patients underwent an RVlead (pace-sense and/or high voltage) extraction and were included in the analysis. In the Evolution group (Group A1 and A2: $\mathbf{n = 4 3}$ ) we extracted a total of 43 leads (18 pace/sense-leads (41.9\%) and 25 highvoltage-leads (58.1\%)) and in the $\mathrm{R} / \mathrm{L}$ group (Group B1 and B2:n=142) a total of 146 leads were extracted (48 pace/sense leads (23.8\%) and 98 high-voltage-leads (69.0\%)). In 4 patients (all R/L group) we extracted both a pace/sense- and a high-voltage-lead. The baseline characteristics of the two different groups are shown in Table 1a. In both groups, patients were predominantly males with similar age at time of extraction and similar systolic LV function. Patients in the Evolution R/L group more frequently underwent extractions due to dysfunction of the lead $(50.0 \%$ vs $27.9 \%, \mathrm{p}<0.001)$, whereas in the Evolution group an infectious cardiovascular implantable electronic device (CIED) $(69.8 \%$ vs $26.1 \%, \mathrm{p}<0.001)$ was the main reason for extraction. Lead-age in the Evolution R/L group was higher. All leads were extracted through the superior subclavian approach. Additional use of the femoral snare was not required because of our stepwise approach with traction and countertraction with a high successrate $(14,15)$ and a snare from a femoral approach enters the right ventricle in a sharp angle, making advancing the femoral snare up to the endocardium difficult and traction and counter traction less effective. The baseline characteristics of Group A1 versus Group B1 are presented in Table 1b. Group A1 (first generation Evolution, with adhesions up to the tip) compared to Group B1 (Evolution R/L, with adhesions up to the tip) consisted of more infections, more pace/sense leads and younger leads. In the groups A2 (first generation Evolution, without adhesions up to the tip) and B2 (Evolution R/L, without adhesions up to the tip) only lead extraction indications differs (Table 1c). Comparing the Evolution and Evolution R/L we encountered a similar percentage of adhesions of the RV lead tip (Table 2). Complete success rate in Group B $(n=142)$ was significantly higher than group A (96.5 vs $76.7 \%, \mathrm{p}=0.0354)$. When comparing Group A1 and B1, patients with adhesions up to the tip of the RV, total complete success is higher in the $\mathrm{R} / \mathrm{L}$ group (61.1\% vs $90.5 \%, \mathrm{p}=0.0067)$ (table 3 ). These differences are mostly due to a significant increase in complete success rate of the Pace/sense leads in favor of the R/L sheath (table 4). Also, when comparing with multivariate analyses, only the use of the R/L Evolution significantly increases the complete success rate with an Beta ratio of 0.340 (CI 0.097-0.0465, p-value $=0.003$ ) corrected for lead age, gender and type of lead (table 5). There were no deaths in our study population. There was no statistically significant difference in major and minor complications between the two groups (Table 6$)$. Overall major complication rates were low $(2 / 185 ; 1.1 \%)$. The minor complications 
in the Evolution group consist of minor asymptomatic pneumothorax $(n=2)$, managed with a drain, in all of the patients. Also 2 puncture-site-related venous haematoma $(n=2)$ were managed conservatively. In the $\mathrm{R} / \mathrm{L}$ type group we observed 2 major complications with tamponade, in need of a thoracotomy and patching of vena cava superior and left atrium. We did not need to use a bridge occlusion balloon. In both cases the R/L evolution sheath was not advanced up to the RV. In the R/L group with adhesions up to the tip of the RV, we observed no major complications and 3 minor complications: 2 puncture-site-related venous haematoma $(\mathrm{n}=2)$ managed conservatively and one asymptomatic pneumothorax, managed conservatively. In the Evolution (Group A) we encountered 6 times clinical success due to a RV-tip residue and one time failure due to a shockcoil stuck behind clavicular bone. In the Evolution R/L (Group B) we encountered 4 times clinical success due to a RV-tip residue and 2-times failure due to a shockcoil, which was removed by sternotomy.DiscussionIn our present prospective single centre series, we studied the feasibility, success and complication rates of lead extraction in case of adhesions of the RV lead up to the lead tip. In a similar cohort of patients, significantly higher complete success rates were achieved when extracting right ventricular leads with adhesions up to the tip, with the novel Evolution R/L sheath in combination with the novel strategy as compared to the Evolution sheath. Furthermore, mechanical extraction towards the endocardium was feasible, and no complications occurred due to the rotational extraction mechanism of the $\mathrm{R} / \mathrm{L}$ sheath when advancing up into the endocardium. Mazzone et al (18) also showed Lead extraction using the Evolution RL bidirectional rotational mechanical sheath and ancillary tools in a systematic stepwise approach was effective and safe, but using the rotational tool up to the myocardium is discouraged. At this moment, dedicated extraction tools for the specific situation where the RV lead is strongly adhered, are limited. Advancing a laser sheath (SLS-II laser sheath) beyond 1cm from the tip of the RV-lead is off label use and cutting through fibrous tissue up to the tip of the RV with the Evolution is discouraged, because of the possibility of perforation of the right ventricle. Push and pull technique with countertraction is the most accepted method up to now. Although in many cases clinical success with a small residual part is a satisfactory result it can be of clinical importance (e.g.: lead endocarditis) to extract the whole system without any remnants. Our study shows that the latter method can be facilitated by subtle bidirectional cutting with the Evolution R/L. With the old Evolution we only felt comfortable applying push and pull with the outer sheath and avoided the usage of unidirectional cutting at the myocardial wall when the tip of the leads was stuck. When using the novel R/L sheath, advancing and cutting within the RV proved to be safe and effective. In multivariate analyses, the use of the $\mathrm{R} / \mathrm{L}$ Evolution sheath was independently associated with complete success $(\mathrm{P}=0.003)$. A significantly higher complete success rate was achieved in high voltage leads compared to pace-sense leads, possibly due to better longitudinal strength. In the $\mathrm{R} / \mathrm{L}$ group the reason for clinical instead of complete success, was mostly fracture of the RV lead 1-2 cm proximal to the tip. Remarkably, in all these cases passive-fixation pacemaker lead was present. No deaths occurred, and only a small and comparable percentage of complications were present in both groups. In patients with strong adhesions at the lead-tip that did not get loose after a few minutes of traction/countertraction, were amenable for subsequent advancement of $\mathrm{R} / \mathrm{L}$ sheath up to the lead tip and myocardium, by applying rotational cutting. This method proved to be feasible and safe, as no direct complications were present related to this manoeuvre. As with all research, our present report has limitations. The reported data represent a single- center prospective registry, with a relatively small number of patients. Complex extraction procedures are, however, not frequently performed, and in the Netherlands, our tertiary cardiology center is one of the largest extraction centers. Direct comparison to other techniques was not performed; certainly, these studies should be performed in the future, but are very complex to realize. International cooperation and merging of databases are essential to obtain more insight into this subject.ConclusionExtraction strategy with the bidirectional Evolution R/L sheath for right ventricular leads with adhesions up to the endocardium is safe and feasible, and associated with higher complete success than with the classic Evolution sheath.

\section{Author contributions:}

Olivier A. Witte: Concept/design, Data analysis/interpretation, Drafting article, Critical revision of article, Statistics, Data collection. Ahmet Adiyaman: Concept/design: Data analysis/interpretation, Drafting article, Critical revision of article, Approval of article, Statistics, Funding secured by, Data collection. Jaap Jan J. 
Smit: Critical revision of article Abdul Ghani: Critical revision of article Anand R. Ramdat Misier: Critical revision of article

Arif Elvan: Critical revision of article

Peter Paul HM Delnoy: Concept/design, Data analysis/interpretation, Critical revision of articleReferences

1. Goldberger Z, Lampert R. Implantable cardioverter-defibrillators: expanding indications and technologies. JAMA 2006;295:809-18.

2. Brignole M, Auricchio A, Baron-Esquivias G, Bordachar P, Boriani G, Breithardt OA, et al; ESC Committee for Practice Guidelines (CPG)., Zamorano JL, Achenbach S, Baumgartner H, Bax JJ, Bueno H, Dean V, et al; Document Reviewers., Kirchhof P, Blomstrom-Lundqvist C, Badano LP, Aliyev F, Bänsch D, Baumgartner H, et al. 2013 ESC Guidelines on cardiac pacing and cardiac resynchronization therapy: the Task Force on cardiac pacing and resynchronization therapy of the European Society of Cardiology (ESC). Developed in collaboration with the European Heart Rhythm Association (EHRA). Europace 2013;15:1070-118.

3. Priori SG, Blomström-Lundqvist C, Mazzanti A, Blom N, Borggrefe M, Camm J,et al; Task Force per il Trattamento dei Pazienti con Aritmie Ventricolari e la Prevenzionedella Morte Cardiaca Improvvisa della Società Europea di Cardiologia. [2015 ESC Guidelines for the management of patients with ventricular arrhythmias and the prevention of sudden cardiac Death. The Task Force for the Management of Patients with Ventricular Arrhythmias and the Prevention of Sudden Cardiac Death of the European Society of Cardiology]. G Ital Cardiol (Rome) 2016;17:108-70.

4. Kusumoto FM, Schoenfeld MH, Wilkoff BL, Berul CI, Birgersdotter-Green UM, Carrillo R, et al. 2017 HRS expert consensus statement on cardiovascular implantable electronic device lead management and extraction. Heart Rhythm 2017;14:e503-e551.

5. Witte OA, Adiyaman A, van Bemmel MW, Smit JJJ, Ghani A, Ramdat Misier AR, et al. Mechanical power sheath mediated recanalization and lead implantation in patients with venous occlusion: Technique and results. J Cardiovasc Electrophysiol 2018;29:316-21.

6. Sohal M, Williams S, Akhtar M, Shah A, Chen Z, Wright M, et al. Laser lead extraction to facilitate cardiac implantable electronic device upgrade and revision in the presence of central venous obstruction. Europace 2014;16:81-7.

7. Deharo JC, Bongiorni MG, Rozkovec A, Bracke F, Defaye P, Fernandez-Lozano I, et al. Pathways for training and accreditation for transvenous lead extraction: a European Heart Rhythm Association position paper. Europace 2012;14:124-34.

8. Wilkoff BL, Love CJ, Byrd CL, Bongiorni MG, Carrillo RG, Crossley GH III, et al. Transvenous lead extraction: Heart Rhythm Society expert consensus on facilities, training, indications, and patient management: this document was endorsed by the American Heart Association (AHA). Heart Rhythm 2009;6:1085-104.

9. Providencia R, Kramer DB, Pimenta D, Babu GG, Hatfield LA, Ioannou A, et al. Transvenous implantable cardioverter defibrillator (ICD) lead performance: a meta-analysis of observational studies. J Am Heart Assoc 2015;4:e002418.

10. Kleemann T, Becker T, Doenges K, Vater M, Senges J, Schneider S, et al. Annual rate of transvenous defibrillation lead defects in implantable cardioverter-defibrillators over a period of $>10$ years. Circulation 2007;115:2474-80.

11. Wazni O, Epstein LM, Carrillo RG, Love C, Adler SW, Riggio DW, et al. Lead extraction in the contemporary setting: the LExICon study: an observational retrospective study of consecutive laser lead extractions. J Am Coll Cardiol 2010;55: 579-86.

12. Bongiorni MG, Soldati E, Zucchelli G, Di Cori A, Segreti L, De Lucia R, et al. Transvenous removal of pacing and implantable cardiac defibrillating leads using single sheath mechanical dilatation and multiple venous approaches: high success rate and safety in more than 2000 leads. Eur Heart J 2008;29:2886-93.

13. Kennergren C, Bjurman C, Wiklund R, Gabel J. A single-centre experience of over one thousand lead extractions. Europace 2009;11:612-7. 
14. Witte OA, Adiyaman A, Smit JJJ, Ramdat Misier AR, Elvan A, Ghani A, et al. Success and complication rates of lead extraction with the first- vs. the second-generation Evolution mechanical sheath. Europace. 2017;19:1717-22.

15. Delnoy PPHM, Witte OA, Adiyaman A, Ghani A, Smit JJJ, Ramdat Misier AR, et al. Lead extractions: the Zwolle experience with the Evolution mechanical sheath. Europace 2016;18:762-6.

16. SLS-II Instruction for use, SPECTRANETICS

17. Evolution R/L Instruction for use, COOK

18. Migliore F, Testolina M, Sagone A, Carretta D, Agricola T, Rovaris G, Piazzi E, Facchin D, De Lazzari M, Zorzi A, Melillo F, Cataldi C, Marzi A, Bottio T, Tarzia V, Gerosa G, Iliceto S, Bertaglia E, Mazzone P. Multicenter experience with the Evolution RL mechanical sheath for lead extraction using a stepwise approach: Safety, effectiveness, and outcome. Pacing Clin Electrophysiol. 2019 Jul;42(7):989-997

Table 1a: Baseline characteristics

\begin{tabular}{|c|c|c|c|c|}
\hline & Total $(n=185)$ & $\begin{array}{l}\text { Evolution } \\
(\mathrm{n}=43=\text { Group } \\
\mathrm{A})\end{array}$ & $\begin{array}{l}\text { Evolution RL } \\
(\mathrm{n}=142= \\
\text { Group B })\end{array}$ & $P$ value \\
\hline $\begin{array}{l}\text { Age at } \\
\text { implantation } \\
\text { Mean } \pm S D\end{array}$ & $57.84 \pm 13.00$ & $59.70 \pm 15.76$ & $57.28 \pm 12.05$ & 0.2248 \\
\hline $\begin{array}{l}\text { Age at extraction } \\
\text { mean } \pm \mathrm{SD}\end{array}$ & $66.30 \pm 13.30$ & $66.67 \pm 16.36$ & $66.18 \pm 12.29$ & 0.6367 \\
\hline $\begin{array}{l}\text { Male gender } \\
\text { L.E. Indication }\end{array}$ & $135 / 185(73.0 \%)$ & $32 / 43(74.4 \%)$ & $103 / 39(72.5 \%)$ & $\begin{array}{l}0.8075 \\
<0.001\end{array}$ \\
\hline Infection & $67 / 185(36.2 \%)$ & $30 / 43(69.8 \%)$ & $37 / 142(26.1 \%)$ & \\
\hline Lead malfunction & $83 / 185(44.9 \%)$ & $12 / 43(27.9 \%)$ & $71 / 142(50.0 \%)$ & \\
\hline Other & $35 / 185(18.9 \%)$ & $1 / 43(2.3 \%)$ & $34 / 142(23.9 \%)$ & \\
\hline $\begin{array}{l}\text { Systolic LV } \\
\text { function }\end{array}$ & & & & 0.5020 \\
\hline severe impairment & $77 / 185(41.6 \%)$ & $16 / 43(37.2 \%)$ & $61 / 142(43.0 \%)$ & \\
\hline $\begin{array}{l}\text { moderate } \\
\text { impairment }\end{array}$ & $29 / 185(15.7 \%)$ & $6 / 43(14.0 \%)$ & $23 / 142(16.2 \%)$ & \\
\hline mild impairment & $31 / 185(16.8 \%)$ & $6 / 43(14.0 \%)$ & $25 / 142(17.6 \%)$ & \\
\hline $\begin{array}{l}\text { normal } \\
\text { Leads } \\
\text { extraction }\end{array}$ & $48 / 185(26.0 \%)$ & $15 / 43(34.9 \%)$ & $33 / 142(23.2 \%)$ & \\
\hline $\begin{array}{l}\text { RV Pace-sense } \\
\text { lead }\end{array}$ & $66(35.7 \%)$ & $18 / 43(41.9 \%)$ & $48 / 142(23.8 \%)$ & 0.3339 \\
\hline $\begin{array}{l}\text { RV shock lead } \\
\text { (ICD) }\end{array}$ & $123(66.5 \%)$ & $25 / 43(58.1 \%)$ & $98 / 142(69.0 \%)$ & 0.1857 \\
\hline $\begin{array}{l}\text { Lead age } \\
\text { (years) }\end{array}$ & & & & 0.0003 \\
\hline $0-2$ & $13 / 185(7.0 \%)$ & $9 / 43(20.9 \%)$ & $4 / 142(2.8 \%)$ & \\
\hline $2-4$ & $24 / 185(13.0 \%)$ & $6 / 43(14.0 \%)$ & $18 / 142(12.7 \%)$ & \\
\hline $4-6$ & $34 / 185(18.4 \%)$ & $11 / 43(25.6 \%)$ & $23 / 142(16.2 \%)$ & \\
\hline $6-8$ & $36 / 185(19.5 \%)$ & $7 / 43(16.3 \%)$ & $29 / 142(20.4 \%)$ & \\
\hline $8-10$ & $30 / 185(16.2 \%)$ & $2 / 43(4.7 \%)$ & $28 / 142(19.7 \%)$ & \\
\hline $\begin{array}{l}\text { Age lead > } 10 \\
\text { years }\end{array}$ & $48 / 185(26.0 \%)$ & $8 / 43(18.6 \%)$ & $40 / 142(28.2 \%)$ & 0.2100 \\
\hline
\end{tabular}

shows baseline characteristics of the two different groups. Table 1b: Baseline characteristics 


\begin{tabular}{|c|c|c|c|}
\hline & $\begin{array}{l}\text { A1 (Evolution with } \\
\text { adhesion) }(\mathrm{n}=18)\end{array}$ & $\begin{array}{l}\text { B1 }(\text { Evolution R/L } \\
\text { with adhersion) }(\mathrm{n}= \\
59)\end{array}$ & $\mathbf{P}$ value \\
\hline $\begin{array}{l}\text { Age at implantation } \\
(\text { mean } \pm \text { SD })\end{array}$ & $60.67 \pm 17.03$ & $57.2 \pm 11.3$ & 0.4942 \\
\hline $\begin{array}{l}\text { Age at extraction } \\
(\text { mean } \pm S D)\end{array}$ & $67.72 \pm 17.39$ & $66.8 \pm 11.7$ & 0.8003 \\
\hline Male gender & $15 / 18(83.3 \%)$ & $45 / 59(76.3 \%)$ & 0.7475 \\
\hline L.E. Indication & & & 0.0020 \\
\hline Infection & $13 / 18(72.2 \%)$ & $16 / 59(27.1 \%)$ & \\
\hline Lead malfunction & $4 / 18(22.2 \%)$ & $25 / 59(42.4 \%)$ & \\
\hline Other & $1 / 18(2.6 \%)$ & $18 / 59(30.5 \%)$ & \\
\hline Systolic LV function & & & 0.4029 \\
\hline severe impairment & $5 / 18(27.8 \%)$ & $20 / 59(33.9 \%)$ & \\
\hline moderate impairment & $2 / 18(11.1 \%)$ & $12 / 59(20.3 \%)$ & \\
\hline mild impairment & $2 / 18(11.1 \%)$ & $11 / 59(18.6 \%)$ & \\
\hline normal & $9 /(50.0 \%)$ & $16 / 59(27.1 \%)$ & \\
\hline \multicolumn{4}{|l|}{ Leads extraction } \\
\hline RV & $11 / 18(61.1 \%)$ & $24 / 59(40.7 \%)$ & 0.1773 \\
\hline $\mathrm{ICD}$ & $7 / 18(38.9 \%)$ & $39 / 59(66.1 \%)$ & 0.0393 \\
\hline Lead age (years) & & & 0.0503 \\
\hline $0-2$ & $4 / 18(22.2$ & $1 / 59(1.7 \%)$ & \\
\hline $2-4$ & $2 / 4(11.1 \%)$ & $7 / 59(11.9 \%)$ & \\
\hline $4-6$ & $4 / 18(22.2 \%)$ & $9 / 59(15.3 \%)$ & \\
\hline $6-8$ & $3 / 18(16.7 \%)$ & $9 / 59(15.3 \%)$ & \\
\hline $8-10$ & $1 / 18(5.6 \%)$ & $12 / 59(20.3 \%)$ & \\
\hline Age lead > 10 years & $4 / 18(22.2 \%)$ & $21 / 59(35.6 \%)$ & 0.2889 \\
\hline
\end{tabular}

shows baseline characteristics of patients with adhesions up to the tip of the RVTable 1c Baseline characteristics

\begin{tabular}{|c|c|c|c|}
\hline & $\begin{array}{l}\text { A2 (Evolution } \\
\text { without adhesion) (n } \\
=25)\end{array}$ & $\begin{array}{l}\text { B2 }(\text { Evolution } \mathrm{R} / \mathrm{L} \\
\text { without adhesion) (n } \\
=83)\end{array}$ & $P$ value \\
\hline $\begin{array}{l}\text { Age at implantation } \\
(\text { mean } \pm \text { SD) }\end{array}$ & $59.00 \pm 15.11$ & $57.3 \pm 12.6$ & 0.3216 \\
\hline $\begin{array}{l}\text { Age at extraction } \\
(\text { mean } \pm \mathrm{SD})\end{array}$ & $65.92 \pm 15.90$ & $65.7 \pm 12.7$ & 0.6805 \\
\hline Male gender & $17 / 25(68.0 \%)$ & $58 / 83(69.9 \%)$ & 0.8581 \\
\hline L.E. Indication & & & 0.0002 \\
\hline Infection & $17 / 25(68.0 \%)$ & $21 / 83(25.3 \%)$ & \\
\hline Lead malfunction & $8 / 25(32.0 \%)$ & $46 / 83(55.4 \%)$ & \\
\hline Other & $0 / 25$ & $16 / 83(19.3 \%)$ & \\
\hline Systolic LV function & & & 0.9469 \\
\hline severe impairment & $11 / 25(44.0 \%)$ & $41 / 83(49.4 \%)$ & \\
\hline moderate impairment & $4 / 25(16.0 \%)$ & $11 / 83(13.3 \%)$ & \\
\hline mild impairment & $4 / 25(16.0 \%)$ & $14 / 83(16.9 \%)$ & \\
\hline normal & $6 / 25(24.0 \%)$ & $17 / 83(20.5 \%)$ & \\
\hline \multicolumn{4}{|l|}{ Leads extraction } \\
\hline $\mathrm{RV}$ & $7 / 25(28.0 \%)$ & $24 / 83(28.9 \%)$ & 0.9293 \\
\hline
\end{tabular}




\begin{tabular}{llll}
\hline & $\begin{array}{l}\text { A2 (Evolution } \\
\text { without adhesion) } \\
\text { = 25) }\end{array}$ & $\begin{array}{l}\text { B2 (Evolution R/L } \\
\text { without adhesion) } \\
\mathbf{=} \mathbf{8 3})\end{array}$ & P value \\
\hline $\begin{array}{l}\text { ICD } \\
\text { Lead age (years) }\end{array}$ & $18 / 25(72.0 \%)$ & $59 / 83(71.1 \%)$ & 0.9296 \\
$0-2$ & $5 / 25(20.0 \%)$ & $3 / 83(3.6 \%)$ & 0.0404 \\
$2-4$ & $4 / 2516.0 \%)$ & $11 / 83(13.3 \%)$ & \\
$4-6$ & $7 / 25(28.0 \%)$ & $14 / 83(16.9 \%)$ & \\
$6-8$ & $4 / 25(16.0 \%)$ & $20 / 83(24.1 \%)$ & \\
$8-10$ & $1 / 25(4.0 \%)$ & $16 / 83(19.3 \%)$ & \\
Age lead $>10$ years & $4 / 25(16.0 \%)$ & $19 / 83(22.9 \%)$ & 0.4606 \\
\hline
\end{tabular}

shows baseline characteristics of patients without adhesions up to the tip of the RV; A2=Evolution, $\mathrm{B} 2=$ Evolution $\mathrm{R} / \mathrm{L}$

Table 2 Prevalence of adhesions:

\begin{tabular}{lllll}
\hline & With adhesion in the RV & Without adhesion in the RV & Total & P-value: \\
\hline Evolution & $17(39.5 \%)$ & $26(60.5 \%)$ & $\mathbf{4 3}$ & 0.8602 \\
Evolution R/L & $60(42,3 \%)$ & $82(57.7 \%)$ & $\mathbf{1 4 2}$ & \\
\hline
\end{tabular}

Table 2 shows that there is no significant difference in prevalence of adhesions up to the RV in the Evolution compared to the Evolution R/L.

Table 3 Success rates overall

\begin{tabular}{lllll}
\hline & Total $(\mathbf{n = 1 8 5})$ & Evolution $(\mathbf{n = 4 3 )}$ & Evolution RL $(\mathbf{n = 1 4 2})$ & $\mathbf{P}$ value \\
\hline Success rates & & & & \\
RV P/S lead complete & $54 / 66(84.9 \%)$ & $11 / 18(61.2 \%)$ & $43 / 48(89.6 \%)$ & 0.0130 \\
RV P/S lead clinical & $11 / 66(16.7 \%)$ & $7 / 18(38.8 \%)$ & $4 / 48(8.3 \%)$ & 0.0065 \\
RV P/S lead failure & $1 / 66(1.5 \%)$ & $0 / 18$ & $1 / 48(2.1 \%)$ & 1.000 \\
ICD lead complete & $116 / 123(94.3 \%)$ & $22 / 25(88.0 \%)$ & $94 / 98(95.9 \%)$ & 0.1479 \\
ICD lead clinical & $4 / 123(3.3 \%)$ & $2 / 25(8.0 \%)$ & $2 / 98(2.0 \%)$ & 0.1833 \\
ICD lead failure & $3 / 123(2.3 \%)$ & $1 / 25(4.0 \%)$ & $2 / 98(2.0 \%)$ & 0.4974 \\
Total complete success & $170 / 185(91.9 \%)$ & $33 / 43(76,7 \%)$ & $137 / 142(96,5 \%)$ & 0.0354 \\
\hline
\end{tabular}

Table 3 shows an overall complete success rate of 96,5\% in case of leads in the RV with the new Evolution $\mathrm{R} / \mathrm{L}$ sheath, which is significantly higher $(\mathrm{p}=0.0354)$ compared to the old Evolution $(76.7 \%)$. Also we observe an significant increase $(\mathrm{p}=0.0130)$ in complete success rate of the Pace/sense leads in favor of the $\mathrm{R} / \mathrm{L}$ sheath (61.2\% VS $89.6 \%)$.

Table 4 Success rates of leads with and without adhesions up to the RV

\begin{tabular}{llll}
\hline & $\begin{array}{l}\text { A1 (Evolution with } \\
\text { adhesion) }(\mathbf{n}=\mathbf{1 8})\end{array}$ & $\begin{array}{l}\text { B1 (Evolution R/L } \\
\text { with adhesion) }(\mathbf{n}=\end{array}$ & P9) \\
\hline $\begin{array}{l}\text { Success rates } \\
\text { RV P/S lead complete }\end{array}$ & $5 / 11(45.5 \%)$ & $20 / 24(83.3 \%)$ & 0.041
\end{tabular}




\begin{tabular}{|c|c|c|c|}
\hline & $\begin{array}{l}\text { A1 (Evolution with } \\
\text { adhesion) }(\mathrm{n}=18)\end{array}$ & $\begin{array}{l}\text { B1 (Evolution } \mathrm{R} / \mathrm{L} \\
\text { with adhesion) }(\mathrm{n}= \\
59)\end{array}$ & $\mathbf{P}$ value \\
\hline RV P/S lead clinical & $6 / 11(54.5 \%)$ & $4 / 24(16.7 \%)$ & \\
\hline RV P/S lead failure & $0 / 11$ & $0 / 24$ & 1.000 \\
\hline ICD lead complete & $6 / 7(85.7 \%)$ & $37 / 39(94.9 \%)$ & 0.398 \\
\hline ICD lead clinical & $0 / 7$ & $0 / 39$ & 1.000 \\
\hline ICD lead failure & $1 / 7(14.3 \%)$ & $2 / 39(5.1 \%)$ & 0.398 \\
\hline \multirow[t]{2}{*}{ Total complete } & $11 / 18(61.1 \%)$ & $57 / 63(90.5 \%)$ & 0.0067 \\
\hline & $\begin{array}{l}\text { A2 (Evolution without } \\
\text { adhesion) }(\mathrm{n}=25)\end{array}$ & $\begin{array}{l}\text { B2 (Evolution } \mathrm{R} / \mathrm{L} \\
\text { without adhesion) (n } \\
=83)\end{array}$ & $\mathrm{P}$ value \\
\hline \multicolumn{4}{|l|}{ Success rates } \\
\hline RV P/S lead complete & $7 / 7(100 \%)$ & $23 / 24(95.8 \%)$ & 1.000 \\
\hline RV P/S lead clinical & $0 / 7$ & $0 / 24$ & \\
\hline RV P/S lead failure & $0 / 7$ & $1 / 24(4.2 \%)$ & 1.000 \\
\hline ICD lead complete & $18 / 18(100 \%)$ & $59 / 59(100 \%)$ & 1.000 \\
\hline ICD lead clinical & $0 / 18$ & $0 / 59$ & \\
\hline ICD lead failure & $0 / 18$ & $0 / 59$ & 1.000 \\
\hline Total complete & $25 / 25(100 \%)$ & $82 / 83(98.8 \%)$ & 1.000 \\
\hline
\end{tabular}

Table 4 shows an significant increase $(\mathrm{p}=0.041)$ in complete success rates of the pace/sense leads with adhesions up to the RV when extracted with the new Evolution R/L Sheath (83.3\% vs $45.5 \%$ ). When there was no adhesion in the RV, both sheaths had similar complete success rates in case of extracting a pace/sense or high voltage lead. Table 5 Output of multivariate analyses

\begin{tabular}{llll}
\hline Variables & Beta & 95\% C.I. & P-value \\
\hline Evolution / Evolution R/L & +0.340 & $+0.097-+0.465$ & 0.003 \\
Lead age & -0.99 & $-0.021-+00.8$ & 0.383 \\
ICD- or pace-sense-lead & -0.198 & $-0.316-+0.034$ & 0.112 \\
Gender & +0.017 & $-0.163-+0.191$ & 0.875 \\
\hline
\end{tabular}

Table 5 shows a multivariate analyses where only the use of the R/L Evolution significantly increases the complete success rate with an Beta ratio of 0.340 (CI 0.097-0.0465, p-value $=0.003$ ) corrected for lead age, gender and type of lead. Table 6: complications: distribution of major and minor complications

\begin{tabular}{lllll}
\hline & Total $(\mathbf{n = 1 8 5})$ & Evolution $(\mathbf{N = 4 3 )}$ & Evolution RL (n=142) & P-value \\
\hline Minor complications & $9 / 185(4.9 \%)$ & $4 / 43(9.3 \%)$ & $5 / 142(3.5 \%)$ & 0.2161 \\
Major complications & $2 / 185(1.1 \%)$ & $0 / 43(0 \%)$ & $2 / 142(1,4 \%)$ & 0.4339 \\
\hline
\end{tabular}

Table 6 shows a low major complications rate of only 1.1\%. There was no statistically difference between the Evolution and Evolution R/L group. The major complications consisted two times a sternotomy in the $\mathrm{R} / \mathrm{L}$ group due to tamponade because of dissection in the VCS / RA and apex of the RV (during traction / counter-traction). All patients survived. Table 4 also shows a low total minor complication rate of $4.9 \%$ 
without a statistically difference between the Evolution and Evolution R/L group. In the Evolution group 2-times pneumothorax, managed with a drain and 2-times a bleeding from the extraction puncture side, managed surgically. In the R/L group 1-times pneumothorax, managed with a drain and 4-times bleeding: 2-times from the extraction puncture side, managed surgically. One time haematothorax, managed with a drain and one time mediastinal haematoom, managed conservatively. 